University of Nebraska - Lincoln

DigitalCommons@University of Nebraska - Lincoln

USDA National Wildlife Research Center - Staff Publications
U.S. Department of Agriculture: Animal and Plant Health Inspection Service

June 2007

\title{
Cameras, Coyotes, and the Assumption of Equal Detectability
}

\author{
Eveline Se Quin Larrucea \\ University of Nevada at Reno \\ Peter F. Brussard \\ University of Nevada at Reno \\ Michael M. Jaegar \\ United States Department of Agriculture, Animal and Plant Health Inspection Service, Wildlife Services, \\ National Wildlife Research Center \\ Reginald H. Barrett \\ University of California at Berkeley, Berkeley, CA
}

Follow this and additional works at: https://digitalcommons.unl.edu/icwdm_usdanwrc

Part of the Environmental Sciences Commons

Se Quin Larrucea, Eveline; Brussard, Peter F.; Jaegar, Michael M.; and Barrett, Reginald H., "Cameras, Coyotes, and the Assumption of Equal Detectability" (2007). USDA National Wildlife Research Center Staff Publications. 702.

https://digitalcommons.unl.edu/icwdm_usdanwrc/702

This Article is brought to you for free and open access by the U.S. Department of Agriculture: Animal and Plant Health Inspection Service at DigitalCommons@University of Nebraska - Lincoln. It has been accepted for inclusion in USDA National Wildlife Research Center - Staff Publications by an authorized administrator of DigitalCommons@University of Nebraska - Lincoln. 


\title{
Cameras, Coyotes, and the Assumption of Equal Detectability
}

\author{
EVELINE SÉQUIN LARRUCEA, ${ }^{\mathbf{1}}$ Department of Biology, Program in Ecology, Evolution and Conservation Biology, University of Nevada at Reno, \\ Reno, $N V$ 89557, USA \\ PETER F. BRUSSARD, Department of Biology, Program in Ecology, Evolution and Conservation Biology, University of Nevada at Reno, Reno, NV \\ 89557, USA \\ MICHAEL M. JAEGER, United States Department of Agriculture, Animal and Plant Health Inspection Service, Wildlife Services, National Wildlife \\ Research Center, Logan, UT 84322, USA, and Department of Environmental Science Policy and Management, University of California at Berkeley, \\ Berkeley, CA 94720, USA \\ REGINALD H. BARRETT, Department of Environmental Science, Policy, and Management, University of California at Berkeley, Berkeley, \\ CA 94720, USA
}

\begin{abstract}
Remote cameras are an increasingly important tool in management and wildlife studies. However, we often do not know if they provide an unbiased sample of populations. Using a marked, radiocollared population of coyotes (Canis latrans) of known social status, we evaluated the influence of temporal (daily and seasonal) and spatial (distance between units, habitat, and proximity to human structures) factors on vulnerability to photo-captures. During 8 unbaited camera sessions of 6 weeks each, we obtained 158 coyote photographs at a photo-capture success rate of $1.6 \%$. We were able to identify not only marked individuals, but also a number of uncollared adults through variation in their pelage. Photo-capture of adults peaked 2 weeks after we established camera stations. Annual success for photographing adult coyotes was greatest during March and April, which corresponded with the dispersal season. The majority of photo-captures occurred at night, and adult photo-captures peaked around midnight, with smaller peaks at dawn and dusk. Rather than reflecting a circadian activity pattern, nighttime captures seemed to reflect when adult coyotes were most vulnerable to photo-capture. Characteristics of camera locations, such as amount of human activity, being on roads versus trails, and habitat type, also influenced the number of photo-captures. We conclude that remote cameras do not always provide an unbiased sample of populations and that animal behavior is important to consider when using these systems. Researchers using camera techniques need to carefully consider when, where, and how cameras are placed to reduce this bias. (JOURNAL OF WILDLIFE MANAGEMENT 71(5):1682-1689; 2007)
\end{abstract}

DOI: $10.2193 / 2006-407$

KEY WORDS activity pattern, camera, Canis latrans, census, coyote, infrared-triggered, photograph, sampling.

Remote photography methods have been used in wildlife studies to address a variety of questions (Cutler and Swann 1999). They are useful for studying behaviors that are too costly or difficult to observe using traditional methods (Kucera and Barrett 1993), are less invasive (Franzreb and Hanula 1995, Van Schaik and Griffiths 1996), less labor intensive (Seydack 1984), and provide permanent documentation of photo-captured animals (Bull et al. 1992, Picman and Schriml 1994). They also gather data during inclement weather, at night, and can reduce observer bias. Additionally, camera units can be left in the field with minimal human attention, potentially providing information on more natural behaviors.

However, studies using remote cameras can present problems, as well. Many studies state concerns that human activity, scent, and presence of equipment could alter animal behavior (Hunt and Ogden 1991, Laurance and Grant 1994, Picman and Schriml 1994, Whelan et al. 1994). Furthermore, behaviorally related biases may influence which animals are photographed. Studies that compare numbers of photographs among species or make estimates of population abundances assume equal detectability for all individuals. However, this rarely has been tested (Cutler and Swann 1999) and is not necessarily true (Séquin et al. 2003). Unequal capture probabilities may affect population esti-

${ }^{1}$ E-mail: esequin@unr.nevada.edu mates (Jacobson et al. 1997, Koerth et al. 1997, Karanth and Nichols 1998) and could influence evaluation of other study objectives (e.g., rates of nest predation and species richness). Thus, there is a need to examine if the timing, location, and setting methods used can create biases in which animals are photo-captured.

Coyotes (Canis latrans) are wary and adaptable animals that exhibit differences in vulnerability to capture related to social status and territoriality (Messier and Barrette 1982; Sacks et al. $1999 a, b)$. Territorial coyotes consist of an alpha pair, the monogamously breeding male and female, other adult coyotes called betas that do not breed, and pups (Gese and Ruff 1997, 1998). Together, alphas and betas make up packs that most often include between 3 and 6 individuals (Allen et al. 1987). Coyote territories are exclusive, maintained year-round, and spaced contiguously across the landscape (Bekoff and Wells 1986; Gese et al. 1996a, b). In contrast, transient coyotes do not hold territories, do not breed, and usually travel alone. They have much larger home ranges than territorial coyotes (Kamler and Gipson 2000) and have been noted to occur most frequently in the interstices between territories (Windberg and Knowlton 1988, Sacks et al. 1999b, Kamler and Gipson 2000). Transient home ranges overlap those of other transients (Kamler and Gipson 2000), and this group often can compose a significant portion of the coyote population (Gese et al. 1996a). 
Table 1. Description of camera trials conducted in 5 coyote territories near Red Bluff, California, USA, 1999-2001.

\begin{tabular}{|c|c|c|c|c|}
\hline \multirow[b]{2}{*}{ Trial } & \multirow[b]{2}{*}{ Dates } & \multirow{2}{*}{$\begin{array}{l}\text { Camera density } \\
\left(\text { cameras } / \mathrm{km}^{2}\right)^{\mathrm{a}}\end{array}$} & \multicolumn{2}{|c|}{ No. of photo-captures } \\
\hline & & & Ad & Juv \\
\hline 1 & Sep-Oct 1999 & 4.0 & 7 & 2 \\
\hline 2 & Nov-Dec 1999 & 4.0 & 23 & 0 \\
\hline 3 & May-Jun 2000 & 8.0 & 15 & 0 \\
\hline 4 & Jul-Aug 2000 & 8.0 & 23 & 46 \\
\hline 5 & Jan-Feb 2001 & 2.0 & 12 & 0 \\
\hline 6 & Feb-Mar 2001 & 2.0 & 11 & 0 \\
\hline 7 & Apr-May 2001 & 0.5 & 10 & 0 \\
\hline 8 & May-Jul 2001 & 4.0 & 5 & 4 \\
\hline
\end{tabular}

${ }^{a}$ We calculated camera density as the total no. of camera locations across the 2 territories used in the trial divided by the total area trapped.

${ }^{b}$ No. of photo-captures was the no. of useable photos of ad or juv obtained during each trial.

It has been shown that alpha coyotes were better able to avoid camera stations than either betas or transients and therefore were underrepresented in photographs (Séquin et al. 2003). Additionally, behaviors specific to each status group meant that all coyotes were more likely to be photographed on the edges of territories rather than in the centers (Séquin et al. 2003). We expand on this topic and evaluate influences of the more technical aspects of setting cameras. Using a marked, radiocollared population of coyotes of known social status (alpha vs. beta and transient), we evaluate the influence of temporal factors (time of d, season, and duration of camera sessions) and spatial factors (habitat characteristics, distance between units, and proximity to human activity and structures) on photo-captures.

\section{STUDY AREA}

We conducted the study near Red Bluff, California, USA, on The Nature Conservancy's 15,180-ha Grey Davis Dye Creek Preserve $\left(40^{\circ} 07^{\prime} \mathrm{N}, 121^{\circ} 45^{\prime} \mathrm{W}\right)$. The preserve adjoined the Tehama Wildlife Area and Lassen Volcanic National Forest and was at the edge of the northern Sacramento Valley. This region characteristically had dry, hot summers and wet, mild winters. The preserve ranged in elevation from $50 \mathrm{~m}$ to $700 \mathrm{~m}$. The lowest elevations were predominantly annual grasslands, whereas the hills and ridges were covered in blue oak (Quercus douglasii) woodland. Several deep, perennial drainages, which supported dense riparian vegetation, ran through the preserve. The preserve was closed to the public, and access was monitored. The majority of wildlife was protected on the preserve, but a hunting operation offered guided hunts for deer (Odocoileus hemionus), feral pigs (Sus scrofa), and game birds.

\section{METHODS}

\section{Equipment}

We used 50 infrared-triggered Trailmaster ${ }^{\mathrm{TM}}$ TM-1500 active camera units (Goodson and Associates Inc., Lenexa, KS; Kucera and Barrett 1993). These consisted of a 35-mm weather-resistant camera, an infrared transmitter, and a receiver. Sensitivity of the units was adjusted by setting the amount of infrared pulses to be missed, which translates into the amount of time the beam needs to be interrupted before the camera is triggered. The receiver recorded the date, time, and number of events. A time delay between photographs can also be set. We used 400-ASA print film with 24 exposures in 2 types of cameras: Yashika AW-Mini (Yashica Corp., Kyoto, Japan; modified by Goodson and Associates Inc.) and Olympus Twin (Olympus Corp., Tokyo, Japan; modified by Goodson and Associates Inc.).

\section{Coyote Status}

We captured and marked coyotes on Dye Creek Preserve with individually color-coded radiocollars (Advanced Telemetry Systems, Isanti, MN) and ear tags beginning in 1998. At the time coyotes were physically captured, we considered breeding females, as determined by visible nipples or lactation, to be potential alphas. We confirmed female status by subsequent radiotelemetry locations at den sites and association with pups and a putative alpha male. We considered males alphas if they were territorial, spent a majority of their time with alpha females, and associated with pups at den sites. We defined betas as adult, resident, nonbreeding animals, and defined transients as nonterritorial adults. We considered coyotes juveniles until they appeared fully grown. We classified juveniles remaining in territories as betas at 1 year of age.

We determined territory boundaries with telemetry locations before the onset of the study (Mitchell 2004). Territory sizes averaged $4-6 \mathrm{~km}^{2}$. We selected 5 territories with collared alpha coyotes for our camera sessions. These 5 territories included marked coyotes belonging to all status groups and covered a $40-\mathrm{km}^{2}$ area. We categorized photocaptured beta and transient coyotes as other adults because we did not collar all coyotes in these status groups.

\section{Field Methods}

We conducted the study between September 1999 and July 2001 in 8 6-week sessions including all biologically relevant seasons (i.e., mating, pup rearing, and dispersal; Table 1). Each session involved 2 territories. In all, we used 5 coyote territories, each in multiple sessions. We scheduled $\geq 1$ week intervals between sessions when no cameras were in the field.

We placed a $0.25-\mathrm{km}^{2}$ grid across selected territories and placed an equal number of cameras into every grid square (Fig. 1). Camera density varied among sessions (Table 1). We placed cameras on trails or dirt roads at locations of coyote sign (i.e., tracks, scat, fur, previous sightings). We attached camera units to wooden stands or available vegetation, with the infrared beam set at a height of 0.25 $\mathrm{m}$. We covered cables between receivers and cameras with aluminum foil to discourage feral pigs and rodents from chewing on them. We set cameras to trigger after a pulse delay of $2(1 \mathrm{sec})$, and used a camera delay of 1 minute to avoid photographing the same individual twice. We set cameras to be active 24 hours/day. We did not use any scents or baits at during these 8 sessions, and used cotton gloves during the set-up process to reduce the amount of human scent left on equipment. We concealed camera units and 


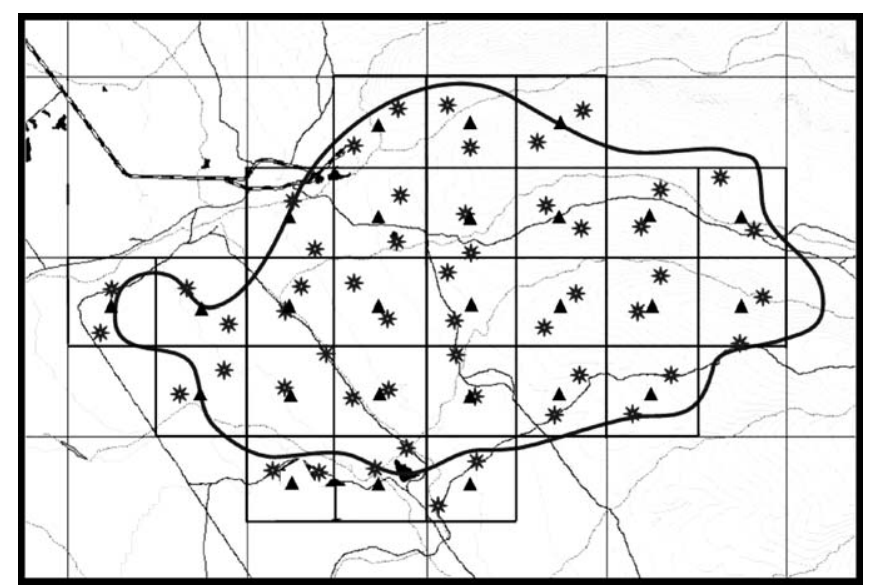

Figure 1. Distribution of camera locations (stars) and observation locations (triangles) using a grid (in this case $0.25 \mathrm{~km}^{2}$ ) overlaying a selected coyote territory, California, USA, 1999-2001. Territory boundaries were determined using radiotelemetry locations and were calculated using adaptivekernel 90\% home-range estimates (Worton 1989).

cables using rocks and surrounding vegetation. After initial placement, we visited all cameras weekly to realign setups, change batteries and film if necessary, and record the dates and times of any photographs.

We conducted 1 additional 6-week camera session February-March 2000, when we set cameras at a density of 4 cameras $/ \mathrm{km}^{2}$. During this session, we baited half the camera stations with a commercial call lure advertised as effective for carnivores. We placed the lure on the ground halfway between the receiver and transmitter. Cameras were otherwise set as in other sessions.
We conducted visual observations concurrently with camera sessions for an independent sample of coyote density. We placed a $0.25-\mathrm{km}^{2}$ grid over territories and used the center of each quadrat as an observation location (Fig. 1). We carried out observations and telemetry from each location twice during a session, once at dawn and once at dusk. Dawn sessions began 1 hour before sunrise, and dusk sessions began 30 minutes before sunset. We recorded numbers of alphas and other coyotes seen. Coyote capture and handling was in accordance with study protocols with University of California Berkeley (R139, R190), the United States Department of Agriculture, Animal and Plant Health Inspection Service, Wildlife Services, National Wildlife Research Center (QA-586), and a Memorandum of Understanding with the California Department of Fish and Game.

\section{Data Analysis}

We categorized camera stations by general habitat type (drainage, ridge, plains), amount of surrounding vegetative cover (high, medium, low), and level of human activity at the site (high, low). We developed exposed film commercially and scanned the negatives with coyotes into a computer for analysis. Although coyotes seemed wary of camera systems and often displayed escape responses, a sensitive pulse-delay setting made it possible to photograph the entire animal. We set cameras along trails and dirt roads, so coyotes were generally photo-captured in flight posture providing a side view of the animal (Fig. 2). This position allowed us to identify individually colored collars easily and to identify individual coyotes (Séquin et al. 2003). Addi-
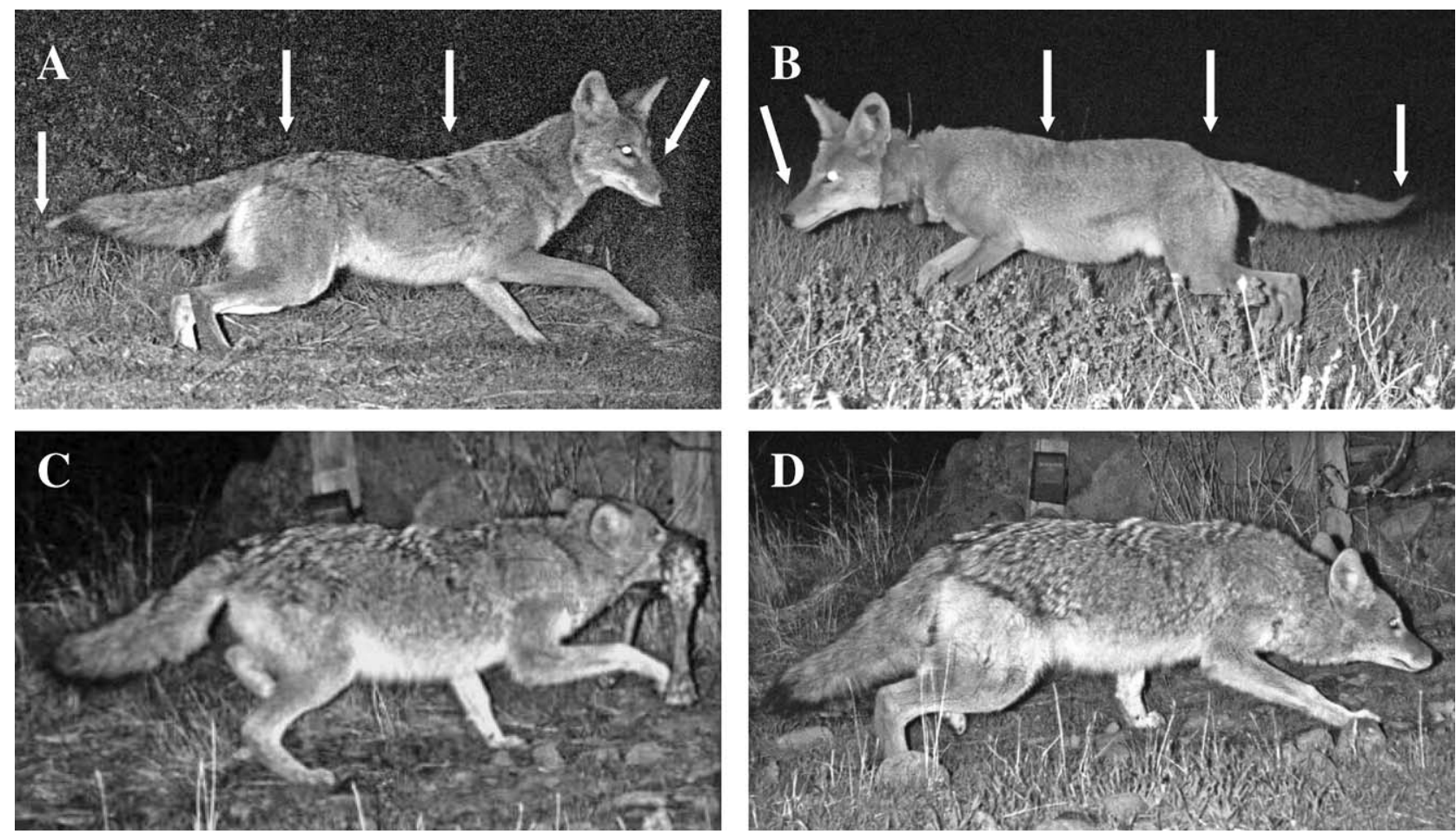

Figure 2. We distinguished individual coyotes from photographs based on variation in coloration of the tip of the tail, base of the tail, amount and locations of white and black banding patterns on backs, and the amount and shape of white around the mouth, California, USA, 1999-2001. Three individuals are depicted in the 4 photographs: individual I in (A), individual II in (B), and individual III in (C) and (D). 


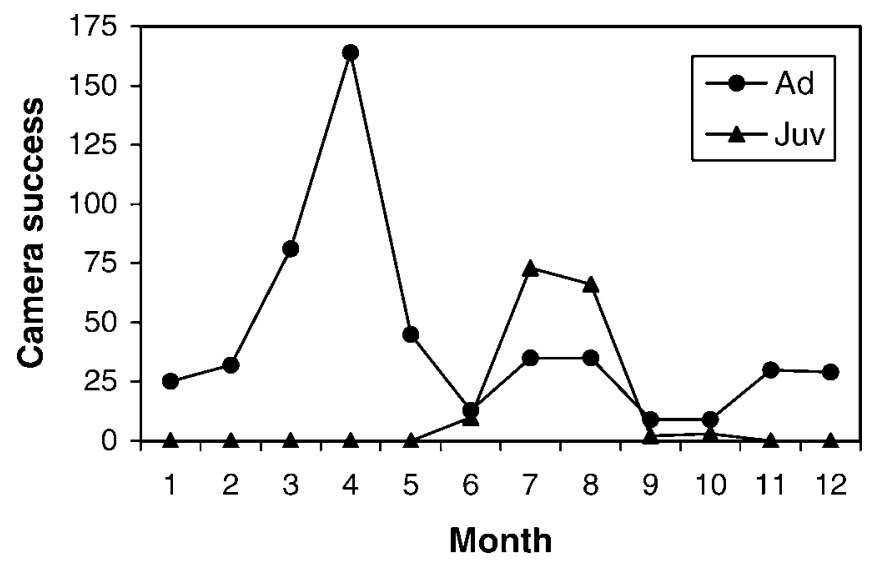

Figure 3. Number of adult and juvenile coyote photographs taken during each month divided by the number of camera stations active during the month (camera success), California, USA, 1999-2001. An active camera station was any camera active for $\geq 85 \%$ of the time during the month.

tionally, coyotes often turned their ears toward cameras, making it possible for us to confirm identities by their numbered ear tags. We enlarged photographs on the computer to identify collar colors, ear-tag numbers, and pelage pattern on the tail, muzzle, and back (Séquin 2001). To determine if coyote pelage markings were symmetrical, we took photographs of left and right sides of 15 known, captive individuals at the United States Department of Agriculture predator research facility at Millville, Utah, USA. We presented these photographs to 5 different observers to evaluate the reliability of identification using pelage markings.

We measured camera success as the total number of coyotes photographed divided by the number of active stations. The number of active stations included cameras that functioned properly $\geq 85 \%$ of the time. We calculated photo-capture success as the total number of coyote captures divided by the total number of active camera-nights (one camera active one night $=$ one camera-night). Our null hypothesis was that all types and locations of camera stations were equally likely to photograph all types of coyotes.

\section{RESULTS}

We placed cameras at 230 different locations in 8 sessions, and $43 \%$ of camera stations photo-captured $\geq 1$ coyote. Other species photographed during the camera sessions included mountain lion (Puma concolor), bobcat (Lynx rufus), gray fox (Urocyon cinereoargenteus), raccoon (Procyon lotor), mule deer (Odocoileus hemionus), feral pig, black bear (Ursus americanus), striped skunk (Mephitis mephitis), opossum (Didelphis virginiana), jackrabbit (Lepus californicus), great blue heron (Ardea herodias), Canada goose (Branta canadensis), greater roadrunner (Geococcyx californianus), ringnecked pheasant (Phasianus colchicus), and wild turkey (Meleagris gallopavo). We set $24 \%$ of cameras in drainages, $19 \%$ on ridges, and $57 \%$ in plains areas. Uncollared adult animals were distinguishable by pelage variation (Fig. 2), and all 5 observers correctly matched the photographs of the

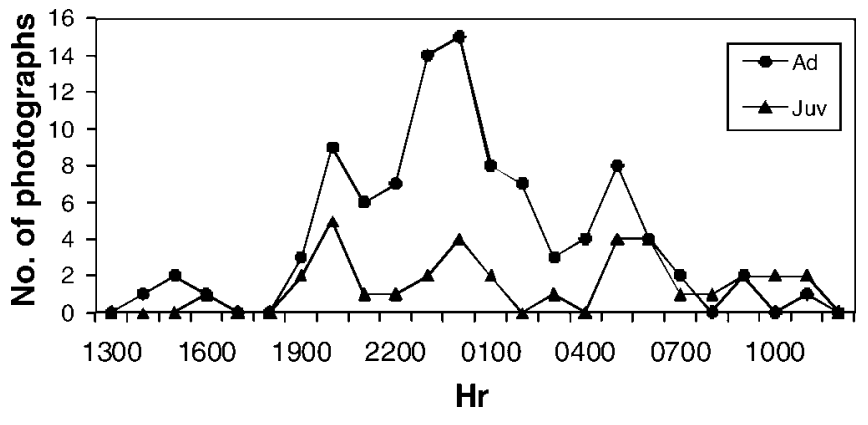

Figure 4. Total number of coyote photo-captures during each 1-hour period over the course of all camera sessions in California, USA, 19992001.

same coyote taken from different sides. We concluded that pelage patterns of coyotes are bilaterally symmetrical.

Adult camera success (no. of ad photo-captures/no. of active camera stations each month) ranged from 0.13 to 2.09, with the highest monthly success occurring MarchApril for adults and July-August for juveniles (Fig. 3). The number of individual coyotes photographed at $>1$ camera station was lower during March-April than during other seasons $\left(\chi_{1}^{2}=4.14, P=0.042\right)$. However, number of collared beta photo-captures during this season did not differ from other seasons $\left(\chi_{1}^{2}=1.38, P=0.24\right)$. Adult photo-captures peaked around midnight, with smaller peaks at dawn and dusk (Fig. 4). Juveniles showed a similar pattern but had higher photo-incidences at dawn and dusk than at midnight (Fig. 4). Time of photo-captures varied among status groups. We obtained only 3 photo-captures of alphas, all taken during the middle of the night $(0007 \mathrm{hr}$, $0210 \mathrm{hr}, 0234 \mathrm{hr}$ ). Beta captures occurred throughout the night, while transient photographs occurred more at dawn and dusk. There was an average of 14 days before a first adult photograph was captured at a camera station. Initial adult captures at individual camera stations peaked during the second week after setup, whereas those of juveniles peaked during the third and fourth weeks (Fig. 5).

We obtained 6 adult photo-captures during the scented session. There was no difference in capture success between scented and unscented cameras $\left(\chi_{1}^{2}=0.16, P=0.68\right)$; however, due to poor angles of photographed individuals, only one photograph obtained during the scented session was useable for individual recognition.

Transients were more likely to be photographed in high vegetative cover than were alphas or betas $\left(\chi^{2}{ }_{2}=6.07, P=\right.$ 0.048). Juvenile coyotes were more likely to be photographed by cameras placed away from familiar man-made objects (e.g., gates, power towers, hunting shacks) $\left(\chi^{2}{ }_{1}=\right.$ $6.04, P=0.014)$. We placed $41 \%$ of cameras on roads and $59 \%$ on game trails. However, more adult coyotes were photographed at cameras set on dirt roads than at cameras set on game trails $\left(\chi^{2}{ }_{1}=42.89, P<0.001\right)$. Distances between receivers and transmitters ranged from $1.1 \mathrm{~m}$ to 5.5 $\mathrm{m}$, and there was no relationship between distance and capture rates $\left(t_{214}=1.42, P=0.079\right)$. There was no difference in receiver-transmitter distances between road or 


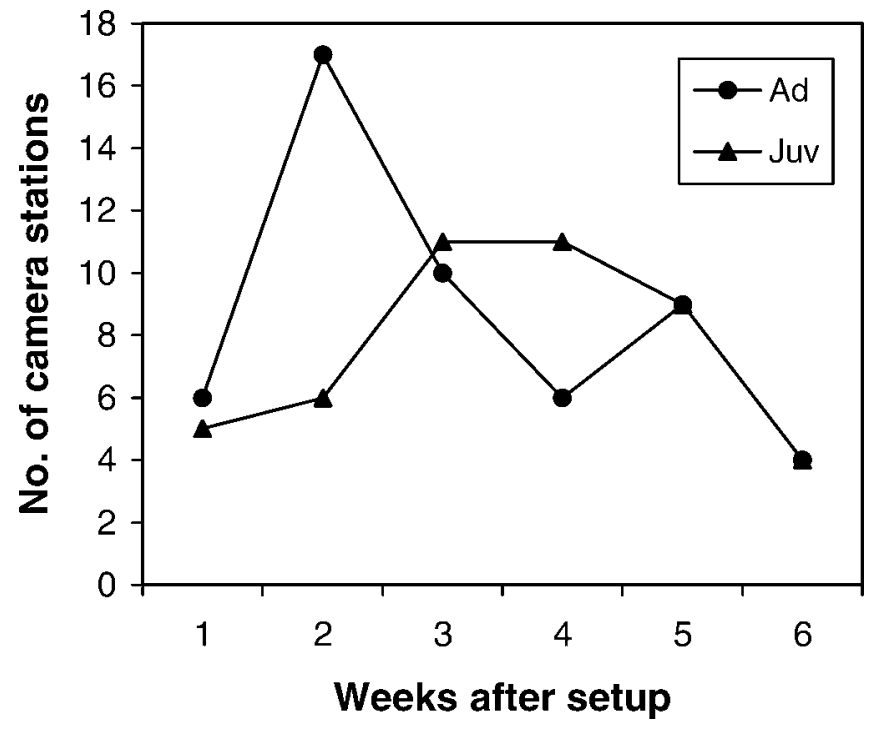

Figure 5. Number of camera stations capturing a first coyote photograph in successive weeks postsetup in California, USA, 1999-2001.

game-trail camera stations $\left(\chi_{1}^{2}=0.16, P=0.69\right)$. There were no differences among habitat types where adults were photographed, but pups were never photographed on ridges $\left(\chi_{2}^{2}=13.59, P=0.001\right)$.

We used photo-capture histories for individuals photographed during trial 2 (fall) and trial 4 (spring) to look at effect of season and session length on population estimates. We entered data as 6 capture events each 1 week in length. Nine individuals were photo-captured in 23 photographs during trial 2, and the closed population model in program CAPTURE (Otis et al. 1978, White et al. 1982) calculated a population estimate of $10(\mathrm{SE}=1.25, \mathrm{CI}=10-16$, Profile Likelihood Interval $[\mathrm{PLI}]=9-14)$. Total area trapped, including a boundary strip to account for individuals captured from outside the trapped area (Wilson and Anderson 1985, Karanth and Nichols 1998) for this session, was $8.9 \mathrm{~km}$ for a density of 1.12 coyotes $/ \mathrm{km}^{2}$. No recaptures occurred during the first week of data collection in trial 2. Data from only the first 2 weeks of trial 2 (length test) provided a population estimate of $16(\mathrm{SE}=12.37, \mathrm{CI}=8$ 72 , PLI $=6-242$ ). Trial 4 had 16 individuals photocaptured in 23 photographs that provided a population estimate of $21(\mathrm{SE}=4.43, \mathrm{CI}=17-36, \mathrm{PLI}=16-36)$. Total area trapped, including boundary strip for this session, was $9.8 \mathrm{~km}$ for a density estimate of 2.14 coyotes $/ \mathrm{km}^{2}$. Data from only the first 2 weeks of trial 4 (length test) provided a population estimate of $22(\mathrm{SE}=17.42, \mathrm{CI}=10-99, \mathrm{PLI}=$ $8-335)$.

\section{DISCUSSION}

\section{Camera Data}

Researchers using camera traps encounter many choices about where and when to place equipment in the field. We demonstrated that these choices can influence the sampling process and potentially lead to biased results. Animal behaviors related to social status (Séquin et al. 2003) and temporal and seasonal activity patterns influence the number of photo-captures, as do actions of the researcher in choosing locations and characteristics of individual camera sites.

Over the course of 9,702 active camera-nights, we obtained 158 useable coyote photographs (Séquin et al. 2003). This represented 42 photo-captures of coyotes of known status from 106 total adult photographs (Séquin et al. 2003). An additional 12 coyote photographs were not useable because the animal was too close to the lens or the image was out of focus or too dark. Uniform side views of coyotes obtained from unbaited cameras placed along dirt roads and game trails permitted comparisons of collared as well as uncollared coyotes. Using natural differences in pelage characteristics, we found enough variation in back, tail, and muzzle color patterns to distinguish among individuals within a season (Fig. 2). We also demonstrated that coyote pelage coloration is symmetrical, meaning that a photograph of one side of an animal was sufficient to distinguish individuals. Additional characteristics such as overall condition and form were also helpful and were useable within a single 6-week camera session. Using these markings allowed us to identify 29 additional individuals from photographs of uncollared adults (Séquin et al. 2003). This was not the case at scented camera stations, where coyotes were generally photographed at poor angles with their faces pointed at the scent. Scenting stations did not improve capture success and made comparisons from all but one photograph impossible. Hence, we used unbaited camera stations for our trials.

\section{Temporal Factors}

Seasonal differences. - Pack membership remained relatively constant, with many individual betas and all alphas remaining present throughout the study. However, population numbers fluctuated seasonally with births, deaths, and dispersals. Coyote density was greatest after the whelping season and declined as pups died or dispersed (Harrison 1992). In contrast, camera success for adults was highest during the spring prior to whelping (Fig. 3). Many young adults disperse at this time and travel great distances through unfamiliar areas, making them more vulnerable to capture (Harris and Knowlton 2001). Dispersing transients may wander through an area only once, leading to a much larger number of individuals in the photographic record than are resident in the area. Most photographs during March and April were single photo-captures of individual, uncollared animals rather than multiple captures of the same individual at different times and stations. The number of known beta captures during this season did not differ from that in other seasons. This increased photo-capture rate coupled with a decreased recapture rate would result in inflated estimates of population numbers. We demonstrated this by compiling individual photo-capture histories for coyotes during different trials as has been done with other species (e.g., tigers [Panthera tigris]; Karanth and Nichols 1998). While both trial 2 (fall) and trial 4 (spring) each obtained 23 adult photo-captures, this represented 9 individuals in the fall trial and 16 individuals in the spring 
trial. Consequently, calculating mark-resight population estimates from fall trial data resulted in a population estimate of 10 and a density estimate of 1.12 coyotes $/ \mathrm{km}^{2}$, and a spring trial population estimate of 21 and a density of 2.14 coyotes $/ \mathrm{km}^{2}$. Although estimates from the fall trial fell within observed density estimates (Séquin et al. 2003), the spring trial greatly overestimated coyote density in the area. Dispersing transients increased photo-capture rates and decreased recapture rates that caused the population density to be overestimated at a time of year when density would be expected to be at its annual low.

Activity patterns.-Observations and telemetry data showed that coyotes did not avoid areas where we had placed cameras. However, all coyotes were generally wary of camera systems and were photo-captured at a low rate of $1.6 \%$ (Séquin et al. 2003). Coyotes remained generally wary of camera systems, and photo-trapping success rates of adult coyotes did not differ between early (1-4) and late (5-8) sessions (Séquin et al. 2003). Adult coyotes were never photographed more than once during a visit to a camera station. Wariness of camera stations was further suggested by the times of day that coyotes were captured (Fig. 4). Other than for capture and release by researchers, Dye Creek Preserve had an unexploited coyote population and coyotes were commonly observed active during daylight. This was confirmed by telemetry data. However, $83 \%$ of adult photographs were taken at night (Séquin et al. 2003). Coyotes rely heavily on visual cues (Wells and Lehner 1978) and may have had more difficulty detecting cameras at night. Disturbance of coyotes due to radiotelemetry work occurred night and day and was not likely to be responsible for the differences observed. Coyotes are reported to be most active around dawn and dusk (Woodruff and Keller 1982), which is consistent with our observations, and corresponds to the secondary peaks at dawn and dusk in the photographic data (Fig. 4). Rather than providing direct evidence of activity patterns, photographic data resulted from a combination of the circadian activity pattern and a relatively greater susceptibility to camera capture under dark conditions.

The fact that different status groups may be more active or more vulnerable at different times of night adds additional bias. Behavioral differences among status groups allowed alpha coyotes to avoid cameras more efficiently than other coyotes; thus, alphas were underrepresented in the photographic record compared to their abundance (Séquin et al. 2003). Juveniles revealed a similar activity pattern to that of adults but did not have the large peak during the midnight hours (Fig. 4). During observation sessions, we observed that juveniles were not as wary of camera systems. Photographs may provide a more accurate pattern of juvenile activity levels.

Duration.-Finally, length of time a camera had been active in the field at a single site affected the number of photo-captures at that site. Individual cameras remained active at a single location for 42 days. The average number of days that passed before a first adult coyote was photographed at an individual camera site was 14 days after initial setup (Fig. 5). Thus, if we had only activated cameras for a week before moving them, we would have missed a large number of photographs. Generally, a single week of data did not provide enough recaptures to calculate population estimates. Only after 2 weeks of data collection, which covered the peak in first photo-capture events of 1012 days, were we able to calculate population estimates. Estimates became more accurate as more weeks of data were incorporated. For example, using trial 2, 2 weeks of data resulted in an estimate of 16 individuals in the population, while 6 weeks of data estimated 10 individuals with a much lower standard error (12.37 vs. 1.25). Human scent left at the sites may have been easier for coyotes to detect during the first 10 days following setup. Later weekly checks involved much less equipment handling and much less time spent at a site. Only after scent had dissipated or until coyotes had become accustomed to cameras did more coyotes get photographed. However, this was not true for all coyotes because alphas never became more susceptible to photo-capture over the course of the 3 years.

\section{Spatial Factors}

Site characteristics. - Specific characteristics of individual camera locations, such as amount of human activity in the vicinity of a site, road versus trail locations, and habitat types, all influenced the number of coyotes photographed. We placed only $24 \%$ of camera stations at sites such as gates, power towers, and hunting shacks that had more human activity associated with them than other locations, but betas and transients were more likely to be photographed at these sites (Séquin et al. 2003). Coyotes may have been less able to detect these cameras due to regular human scent in the area. Similarly, there was more human activity on dirt roads compared to game trails, and although there were no differences among status groups in on-road versus off-road observations (Séquin et al. 2003), coyotes were more likely to be captured at stations placed on roads. Pups were more likely to be photographed at nonanthropogenic sites, probably because den sites were located far away from these sites. Alphas were never photographed at sites with human activity or on roads, although they were frequently observed using these areas.

Size as well as locations of objects can influence neophobia in coyotes (Harris 1983, Windberg and Knowlton 1990, Windberg 1996, Harris and Knowlton 2001). We set receivers and transmitters across roads or game trails, and camera units had to be carefully fitted to each location. There was a slight tendency for adult coyotes to be captured at stations with greater distances between receivers and transmitters. Coyotes may have been more wary of walking between 2 closely spaced objects and were more likely to detour around these setups (Musiani and Visalberghi 2001). However, there were no overall differences in camera set-up distances across game trails as compared to roads, so this did not account for the differences in coyote captures at these sites.

Camera stations fell into 3 broad habitat categories: 
drainages, ridges, and plains. Although studies have noted that coyotes prefer open habitat (Kamler and Gipson 2000), and this preference was supported by telemetry locations, betas were photographed in all habitat types. Transients may have been photographed in areas with greater vegetative cover possibly because they were pushed into suboptimal habitat types by territorial animals that they were avoiding (Kamler and Gipson 2000). However, we feel it is more likely that transients were skirting edges of territories, and these boundaries often fell along the edges of prominent features that included streams and canyons with greater amounts of vegetation.

Territory boundaries. - With $>3$ years of telemetry data on locations of territorial boundaries (Mitchell 2004), we were able to plot relationships of photo-captures to home ranges and found that where coyotes were photographed was influenced by territory boundaries (Séquin et al. 2003). Depending on where cameras were placed, they either photographed a large sample of the population (i.e., on a territory edge, capturing transients, betas, and an occasional alpha), or a highly biased sample (i.e., near a territory center, capturing only a few betas).

In conclusion, we found that animal behavior can affect photo-samples, and when and where cameras are placed into the field needs to be considered carefully. We realize coyotes are known for their intelligence and wariness, and it was not surprising to find differences in their photo-capture rates. Other species may not present as many difficulties. Nevertheless, we suggest that animal behavior is an important consideration when using camera systems to study any species. In multispecies studies, many different behaviors need to be considered.

\section{MANAGEMENT IMPLICATIONS}

To capture as random a subset of the population as possible, it is important to consider differences in seasonal and daily activity patterns. Ideally, cameras should be allowed to run 24 hours/day, and samples should be taken during every season of the year. We realize there are situations where this may not be appropriate or necessary. However, 24-hour sampling should be considered at the onset of new studies to determine if photo-captures occur as expected. Camera locations should cover an expansive area, either all at once or with a smaller number of cameras over a longer period of time. Most studies that use cameras do not have information on home-range or territory-boundary locations. It is therefore important to sample a large enough area to incorporate multiple individuals and any habitat and home-range boundary effects. A variety of camera sites also will sample a broader section of the population. Finally, cameras should be left at each individual location for a long enough period to let wary animals acclimate to them. The optimal length will vary with the species being studied. However, even after taking all these precautions, alpha animals may still be underrepresented in a photographic sample (Séquin et al. 2003). This violates the assumption of equal detectability. Therefore, camera-based estimates may only be able to provide a minimum density, and this only if animals are uniquely identifiable.

\section{ACKNOWLEDGMENTS}

Funding and equipment were provided in large part by the United States Department of Agriculture, National Wildlife Research Center through cooperative agreements with the University of California at Berkeley (7405-0235 CA). Special thanks go to B. Mitchell, who shared background data collected for his Ph.D. Dissertation at University of California at Berkeley that made this study possible. We thank W. Longland and R. Rust for reviewing earlier drafts of this manuscript, and D. Simpson for helping with coyote captures. Additionally, we thank the different agencies and staff working at Dye Creek Preserve for their cooperation and help: The Nature Conservancy, Multiple Use Managers, and Denny Land and Cattle Company.

\section{LITERATURE CITED}

Allen, S. H., J. O. Hastings, and S. C. Kohn. 1987. Composition and stability of coyote families and territories in ND. Prairie Naturalist 19: 107-114.

Bekoff, M., and M. C. Wells. 1986. Social ecology and behavior of coyotes. Advanced Study of Behavior 16:251-338.

Bull, E. L., R. S. Holthausen, and L. R. Bright. 1992. Comparison of three techniques to monitor marten. Wildlife Society Bulletin 20:406-410.

Cutler, T. L., and D. E. Swann. 1999. Using remote photography in wildlife ecology: a review. Wildlife Society Bulletin 27:571-581.

Franzreb, K. E., and J. L. Hanula. 1995. Evaluation of photographic devices to determine nestling diet of the endangered red-cockaded woodpecker. Journal of Field Ornithology 66:253-259.

Gese, E. M., and R. L. Ruff. 1997. Scentmarking by coyotes, Canis latrans: the influence of social and ecological factors. Animal Behavior 54:11551166.

Gese, E. M., and R. L. Ruff. 1998. Howling by coyotes (Canis latrans): variation among social classes, seasons, and pack sizes. Canadian Journal of Zoology 76:1037-1043.

Gese, E. M., R. L. Ruff, and R. L. Crabtree. 1996a. Social and nutritional factors influencing the dispersal of resident coyotes. Animal Behavior 52: 1025-1043.

Gese, E. M., R. L. Ruff, and R. L. Crabtree. 1996b. Foraging ecology of coyotes (Canis latrans): the influence of extrinsic factors and a dominance hierarchy. Canadian Journal of Zoology 74:769-783.

Harris, C. E. 1983. Differential behavior of coyotes with regard to home range limits. Dissertation, Utah State University, Logan, USA.

Harris, C. E., and F. F. Knowlton. 2001. Differential responses of coyotes to novel stimuli in familiar and unfamiliar settings. Canadian Journal of Zoology 79:2005-2013.

Harrison, D. J. 1992. Dispersal characteristics of juvenile coyotes in Maine. Journal of Wildlife Management 56:128-138.

Hunt, R. H., and J. J. Ogden. 1991. Selected aspects of the nesting ecology of American alligators in the Okefenokee Swamp. Journal of Herpetology 25:448-453.

Jacobson, H. A., J. C. Kroll, R. W. Browning, B. H. Koerth, and M. H. Conway. 1997. Infrared-triggered cameras for censusing white-tailed deer. Wildlife Society Bulletin 25:547-556.

Kamler, J. F., and P. S. Gipson. 2000. Space and habitat use by resident and transient coyotes. Canadian Journal of Zoology 78:2106-2111.

Karanth, K. U., and J. D. Nichols. 1998. Estimation of tiger densities in India using photographic captures and recaptures. Ecology 79:28522862.

Knowlton, F. F., E. M. Gese, and M. M. Jaeger. 1999. Coyote depredation control: an interface between biology and management. Journal of Range Management 52:398-412.

Koerth, B. H., C. D. McKown, and J. C. Kroll. 1997. Infrared-triggered camera versus helicopter counts of white-tailed deer. Wildlife Society Bulletin 25:557-562. 
Kucera, T. E., and R. H. Barrett. 1993. The Trailmaster camera system for detecting wildlife. Wildlife Society Bulletin 21:505-508.

Laurance, W. F., and J. D. Grant. 1994. Photographic identification of ground nest predators in Australian tropical rainforest. Wildlife Research 21:241-248.

Messier, F., and C. Barrette. 1982. The social system of the coyote (Canis latrans) in a forested habitat. Canadian Journal of Zoology 60:1743-1753.

Mitchell, B. R. 2004. Coyote vocal communication and its application to the selective management of problem individuals. Dissertation, University of California, Berkeley, USA.

Musiani, M., and E. Visalberghi. 2001. Effectiveness of fladry on wolves in captivity. Wildlife Society Bulletin 29:91-98.

Otis, D. L., K. P. Burnham, G. C. White, and D. R. Andreson. 1978. Statistical inference from capture data on closed animal populations. Wildlife Monographs 62.

Picman, J., and L. M. Schriml. 1994. A camera study of temporal patterns of nest predation in different habitats. Wilson Bulletin 106:456-465.

Sacks, B. N., K. M. Blejwas, and M. M. Jaeger. 1999a. Relative vulnerability of coyotes to removal methods on a northern California ranch. Journal of Wildlife Management 63:939-949.

Sacks, B. N., M. M. Jeager, J. C. Neale, and D. R. McCullough. 19996. Territoriality and breeding status of coyotes relative to sheep predation. Journal of Wildlife Management 63:593-605.

Séquin, E. S. 2001. The influence of social status on coyote vulnerability to photo-capture. Thesis, University of Nevada, Reno, USA.

Séquin, E. S., M. M. Jaeger, P. F. Brussard, and R. H. Barrett. 2003. Wariness of coyotes to camera traps relative to social status and territory boundaries. Canadian Journal of Zoology 81:2015-2025.

Seydack, A. H. W. 1984. Application of a photo recording device in the census of larger rain forest mammals. South African Journal of Wildlife Research 14:10-14.

Van Schaik, C. O., and M. Griffiths. 1996. Activity periods of Indonesian rain forest mammals. Biotropica 28:105-112.

Wells, M. C., and P. N. Lehner. 1978. The relative importance of the distance senses in coyote behavior. Animal Behavior 26:251-258.

Whelan, C. J., M. L. Dilger, D. Robson, N. Hallyn, and S. Dilger. 1994. Effects of olfactory cues on artificial-nest experiments. Auk 111:945-952.

White, G. C., D. R. Anderson, K. P. Burnham, and D. L. Otis. 1982. Capture-recapture and removal methods for sampling closed populations. Los Alamos National Laboratory Publication LA-8787-NERP, Los Alamos, New Mexico, USA.

Wilson, K. R., and D. R. Anderson. 1985. Evaluation of density estimators of small mammal population size. Journal of Mammalogy 66:13-21.

Windberg, L. A. 1996. Coyote responses to visual and olfactory stimuli related to familiarity with an area. Canadian Journal of Zoology 74:22482253.

Windberg, L. A., and F. F. Knowlton. 1988. Management implications of coyote spacing patterns in southern Texas. Journal of Wildlife Management 52:632-640.

Windberg, L. A., and F. F. Knowlton. 1990. Relative vulnerability of coyotes to some capture procedures. Wildlife Society Bulletin 18:282290.

Woodruff, R. A., and B. L. Keller. 1982. Dispersal, daily activity and home range of coyotes in southeastern Idaho. Northwest Science 56:199-207.

Worton, B. J. 1989. Kernel methods for estimating the utilization distribution in home range studies. Ecology 70:164-168.

Associate Editor: Whittaker. 